\title{
TESTING THE EFFECTS OF HEALTHCARE ALLOWANCE COMPENSATION ON NURSING PROFESSION AND JOB SATISFACTION ON WORK PERFORMANCE THROUGH ORGANIZATIONAL COMMITMENT: A STUDY ON NURSING PROFESSION AT TYPE-A HOSPITALS IN JAKARTA AREA
}

\author{
Prasetya Riang, Syah Tantri Yanuar Rahmat \\ Faculty of Economic and Business, University of Esa Unggul, Indonesia \\ *E-mail: riangprasetya@icloud.com
}

\begin{abstract}
In healthcare system as in hospitals, nurses play integral role to provide all healthcare services in a hospital at its optimum. The nurses' twenty-four hours availability of services in hospitals has made them the most common healthcare persons. Nurses' work performance is nurses' activity in implementing command, tasks, and responsibilities at its best in order to achieve and manifest their professional goals and the organizational unit goals. The purpose of the study is to identify the effects of healthcare allowance compensation received by the nurses and the nurses' job satisfaction on their own work performance through organizational commitment as the mediating variable. The study applies questionnaire as the instrument to collect data and process the data by applying Structural Equation Model (SEM) to conduct empirical test on model of the study, which is respondents who work as nurses in type-A hospitals in Jakarta area. The results of the study indicate that the healthcare allowance compensation affects the organizational commitment; the job satisfaction affects the organizational commitment; the healthcare allowance compensation does not affect the nurses' work performance; the job satisfaction affects the nurses' work performance; the organizational commitment affects the nurses' work performance; and the organizational commitment mediates the correlation of the healthcare allowance compensation and job satisfaction on the nurses' work performance.
\end{abstract}

\section{KEY WORDS}

Healthcare allowance compensation, job satisfaction, work performance, organizational commitment, nurse.

Nurses, as part of healthcare system in every hospital, play integral role in order to provide healthcare services at its optimum. It is related to the nurses' twenty-four hours availability of services in hospitals has made them the most common healthcare persons with the percentage of 40 to 60 percent (Swansburg, 2000). There are fundamental factors that affect the nurses' work performance; one of them is the healthcare allowance compensation. It is fundamental because it affects the nurses' behavior as the employees of hospitals to do their best at work and it can excel their work performance. The charge nurses' work performance is the main factor in achieving the optimal service in hospitals. Nurses' work performance is nurses' activity in implementing command, tasks, and responsibilities at its best in order to achieve and manifest their professional goals and the organizational unit goals. A fair and reasonable compensation affects the level of a nurse's organizational commitment on one's job. The compensation that is investigated and analyzed in the current study is the healthcare allowance compensation. The researchers focus on the measurement of the effects of the healthcare allowance compensation, which is under the Indonesia laws and regulations (legally required benefit), namely the employees' participation in BPJS Kesehatan program (Indonesia's national healthcare allowance).

There are five factors that can be applied to improve a nurse's work performance like job promotion, job evaluation, working environment and supporting facilities, motivation and compensation, and opening the chance to continue the education to the next level (Fort dan Voltero, 2004). Job satisfaction on a nurse is an essential concept within the general job satisfaction level, even though some previous studies point out that every job satisfaction has 
similarities based on several indicators like physical condition during work, the relation between nurses, salary, work insurance e.g. healthcare allowance, job promotion, and responsibility.

A study conducted by Gunlu et al. (2009) finds out that the job satisfaction affects the organizational commitment. Next, Anari et al. (2011) point out that the job satisfaction has positive effect on the organizational commitment. Furthermore, a study conducted by Nawab et al. (2011) underlines that the healthcare allowance compensation has positive effect on the level of the employees' organizational commitment. In addition, Obasan (2012) shows that the healthcare allowance compensation has positive effect on the employees' work performance. Khan et al. (2012) point out that the job satisfaction has positive effect on the employees' work performance. Then, a study conducted by Khan et al. (2016) underlines that the organizational commitment has positive effect on the improvement of the employees' work performance. Funmilola et al. (2013) show that the job satisfaction has positive effect on the employees' work performance. Additionally, Muhammad et al. (2016) find out that the organizational commitment has positive effect on the employees' work performance.

The current study might open some ideas in both academic and practical aspects. In academic aspect, the current study covers some impressions on the development in management studies. For examples, the policy implementation and an organization plan on the healthcare allowance compensation, the job satisfaction that in relation to the organizational commitment, the nurses' work performance, and the reference for further studies in management or other fields of study. Furthermore, in practical aspect, the current study might offer alternative solution of any problems faced by an organization, specifically private hospitals. The solution is expected to be effective if the problems are related to the healthcare allowance compensation and the job satisfaction that in relation to the nurses' organizational commitment and its effect on the nurses' work performance at the hospitals.

\section{LITERATURE REVIEW}

In general, literatures of related studies point out there are three types of compensation, i.e. direct compensation, indirect compensation, and incentive (Sinambela, 2016). Direct compensation is defined as a reward in a scheme of salary or fee, which is paid regularly based on a period of time that has been set by the organization. Indirect compensation is a plan to share profits or benefits to workers apart from fixed salary or fee, in a scheme of money or properties. Furthermore, incentive is a reward shared to the workers to motivate them so they are encouraged to raise their productivity. Incentive characteristic is not fixed, of which it is unexpectedly. Ruby (2012) defines indirect compensation as an indirect financial and/or non-financial payment received by the employees as long as they keep working for a company. The other words for indirect compensation are fringe benefits, employee services, supplementary compensation and supplementary pay. Ruby also states that indirect compensation or employee benefit is a part of remuneration elements shared to the employees as additional expenses of any payment by cash. In addition, Ruby (2012) underlines that there are many organizations offer some prevalent types of indirect compensation. First, sosial security that aims to provide financial security to the employees as they enter their retirement. Both the employers and employees play role in the social security payment by paying it based on the percentage that has been set by the government. Second, the disability insurance that aims to protect the employees from losing their income and accidents that happened to them or the illness that may disrupt their working activities.

Satisfaction is inseparable from an individual's attitude on someone or something. Many researchers state that an individual might have thousands of attitudes. In relation to the organizational behavior, the researchers divide it into three attitudes: job satisfaction, job involvement, and organizational commitment. Khuong and Tien (2013) define job satisfaction as a positive emotional statement as a result of an employee's job evaluation or job experience. A study conducted by Pandey (2012) defines job satisfaction as a positive attitude that occurs within an employee's self in relation to the job or job situation. 
Furthermore, Robbins (2006) determines job satisfaction as a positive feeling on one's job based on its characteristic evaluation. Whereas Glinow and Mcshane (2008) underline that the job satisfaction manifests in the nurses' evaluation on their job and job contexts, which becomes the popular subject of research interests. Job satisfaction is an evaluation about the perception on the job characteristic, working environment, and emotional experience in the workplace. In relation to the current study, job satisfaction is the nurses' attitude on several aspects and contexts of the job.

Organizational commitment is essential factor of the success of organizational success. When employees are fully committed to the organization, they will be loyal to the organization and contribute their best at work. In relation to the current study, the nurses' loyalty is implemented in their willingness to perform their best at work and to keep themselves as a part of the organization. The concept of organizational commitment is related to the degree to which an individual's involvement in the organization one works for and still fully committed to stay in the organization. Sopiah (2008) also states another view on organizational commitment, of which a characteristic of commitment is not only passive loyalty, but also involve active interaction with the organization as a means to support the organization to achieve success.

Organizational commitment is a psychological relation between the employees and the organization they work for, which is implemented by accepting and doing any given tasks, and it encourages the employees strongly to stay in the organization (Anindita and Seda, 2017). Based on abovementioned definitions, organizational commitment can be defined as an event in which the employees' loyalty is demonstrated by keep working for the organization and exert their utmost effort to achieve the goals and values of the organization. In other words, organizational commitment is viewed as an attitude that depicts workers loyalty and their devotion to the continuity, success, and prosperity of the organization. Based on aforementioned point of views on the organizational commitment, it can be described as an employee's ability to identify oneself with the values, the rules, and the goal of the organization that covers loyalty and the involvement in any kind of job-related activities.

Work performance is a very essential aspect that needs special attention from the management, either in a small or large company. Any results achieved by an organization or employees are the reflection of the responsibility to the organization and public. Work performance cannot be functioned solely in contributing to the success of the company as it is always related to the employees' job satisfaction and the level of given rewards. Furthermore, it is supported by skills, abilities, and the personality traits of each individuals.

Sedarmayanti (2011) states that the work performance is defined as the work result done by an employee. For instance, a process in a management or the organization as a whole in which its result is tangible and measurable, when it is compared to the standard that has been set. If a work performance does not present, then the all units in an organization will far from achieving their goals.

Robbins (2006) states that other term of work performance is human output, of which it is measured from the productivity, absenteeism, turnover, citizenship, and satisfaction. Furthermore, Baron and Greenberg (1990) point out that work performance in an individual is also termed as job performance, work outcomes, and task performance. In addition, work performance can be viewed as a goal achievement of an organization, which is implemented in either quantitative or qualitative output, creativity, flexibility, trustworthy, and other outputs that are expected by the organization.

Work performance is applicable for both short term and long term period of time. It is also implemented within an individual, a group, or an organization. Work performance management is a process designed to create synchronization between the goal of the organization and the goal of the individual, so they are on the same page. In addition, work performance is also viewed as an action or accomplished assignment in a specific period of time, which is measurable. 
There are four elements in work performance, i.e. results of the work function, factors that affect an employee's achievement, the goal achievement of the organization, and a specific period of time.

Mutual concession or give-and-take from the management regarding the tasks fulfilled by the nurses should be considered important in the first place, as it keeps the nurses' high commitment to the job. Every employee or every nurse in a hospital has a desire to receive compensation that meets each individual's ideal requirement. If their expectation fulfilled, it will encourage them to have high commitment at work. If the received healthcare allowance is worthy, the employees are satisfied and driven to achieve the vision and mission of the organization. Simamora (2004) states that a good compensation is a compensation share system that is responsive to a situation and able to motivate employees. Therefore, the available compensation system is expected to meet employees' desire to ensure their rights in receiving compensation are fairly shared. In addition, rewards are also set as it reflects their effort in doing their job for the organization. Hence, the fair and worthy compensation will motivate the nurses to do their best effort at work. Moreover, the employees perceive the appreciation for their best determination at work from the organization, as the result of fair and worthy shared compensation. The appreciation will generate high commitment within the nurses in doing their best at work. Any jobs executed with high commitment will result in great achievement as it resonates with the goals of the hospital management. Several researchers elicit that the healthcare allowance compensation can increase the organizational commitment of the nurses or the employees when they do their job. Nawab et al. (2011) point out that the indirect compensation has positive correlation on the organizational commitment. The more deserving the given indirect compensation, the more the nurses increase their organizational commitment. The other study conducted by Ahmad et al. (2016) also underlines that the indirect compensation is a vital factor that has impact on the increase of the organizational commitment.

Based on the previous explanations and the empirical evidence in the abovementioned studies, researchers propose a statement that is formulated in the following hypothesis:

$\mathrm{H}_{1}$ : A worthy shared healthcare allowance compensation can increase the organizational commitment

The job satisfaction and the organizational commitment are related, but both principles are different attitudes. For instance, there is a brief period of time when a nurse may feel discouraged in doing one's task, but still fully committed to the organization. In previous studies, the researchers point out that the high job satisfaction can increase the nurses or the employees' organizational commitment in an organization. Wang et al. (2012) underline that the high job satisfaction can increase the nurses' commitment on the organization. A study conducted by Anari (2011) also highlights that the high job satisfaction supported by several parameters such as salary, supervision, working environment, and the job itself can affect the increase of the organizational commitment of the employees. Nahas et al. (2012) find out that the job satisfaction has positive effect on the organizational commitment. The higher the job satisfaction the more the employees or the nurses motivate themselves to strengthen their commitment to the organization. A study conducted by Gunlu (2009) also highlights that the high job satisfaction affects the organizational commitment.

Based on the previous explanations and the empirical evidence in the abovementioned studies, researchers propose a statement that is formulated in the following hypothesis:

$\mathrm{H}_{2}$ : The high job satisfaction can increase the nurses' organizational commitment.

A nurse is motivated to undertake any given task as the individual expects the worthy reward. The expectation for bonuses, salary increase, promotion, and appreciation are the examples of financial and non-financial compensations. It indicates that these aspects of the compensations affect to the degree to which an individual is fully committed to one's job. However, the current study finds out that the healthcare allowance compensation does not affect the work performance. The result of the current study is in contrast to the previous studies. A study conducted by Syahreza et al. (2017) highlight that the indirect compensation affects the improvement of the employees' work performance. Okwudili et al. (2017) also 
states that either a direct compensation or indirect compensation affects the improvement of the employees' performance respectively or in unison. In addition, Obasan (2012) finds out that there is positive correlation between the indirect compensations on the work performance.

Based on the previous explanations and the empirical evidence in the abovementioned studies, researchers propose a statement that is formulated in the following hypothesis:

$\mathrm{H}_{3}$ : The shared healthcare allowance does not affect the nurses' work performance.

In general, an evaluation on the job satisfaction in an organization is a manifestation of the accumulation of employees' feelings or attitudes on their job. The employees' feelings and attitudes are related to the working environment, type of job, compensation, the relation between coworkers, social relation at workplace, and so on. Accordingly, it is underlined that the job satisfaction is a condition in which the employees' desires and needs related to their job are fulfilled.

A nurse who is satisfied with one's own job, the working environment, and the worthy compensation will be highly motivated in doing one's job. High motivation will encourage an employee in increasing one's target in doing their job, so it can raises the employee's work performance as a whole. Previous studies highlight that the employees' job satisfaction encourages optimal work performance. A study conducted by Nanda and Brown (1977) underlines that the job satisfaction level and motivation will affect the employees' productivity. Furthermore, the low job satisfaction level has negative effect on the employees' commitment, the achievement of the goal of the organization, and the employees' work performance (Meyer, 1999). In addition, Gunawan et al. (2018) find out that the high job satisfaction has positive effect on the lecturers' work performance in the Sekolah Tinggi Ilmu Pelayaran (Cruise Ship Academy) - Jakarta. Barasa et al. (2018) also state that the high job satisfaction has positive effect on the improvement of the employees' work performance who work in a port in Jakarta area. Additionally, Funmilola et al. (2013) highlights that the job satisfaction has positive effect on the employees' work performance. An employee who is satisfied with one's own job will do one's utmost effort to the achievement of the vision and mission of an organization.

Based on the previous explanations and the empirical evidence in the abovementioned studies, researchers propose a statement that is formulated in the following hypothesis:

$\mathrm{H}_{4}$ : High job satisfaction will increase the nurses' work performance.

An employee or a nurse who has commitment to the organization has exceptional behavior from the other employees who have low commitment to the organization. The commitment that grows within the employee self has positive effect on the organization, such as the employees' great work performance. By having high commitment, a nurse has the sense of belongings in relation to the organization he/she works for, and it is implemented by the individual's voluntary involvement in any activities held by the organization.

An employee who has high commitment to the organization will put the vision and mission of the organization as first priority instead of one's own interests and ambition. Eventually, having high commitment to the organization will generate positive behaviors, like keeping the corporate reputation, loyalty to the leaders, being cooperative and positive towards coworkers, and have a good intention to solve any problems through discussion board. These constructive conditions will be very useful in improving the nurses' work performance. A good work performance will also improve the work performance of the organization. In relation to the subject of the current study, the vision and mission of the organization can be achieved if the nurses have excellent work performance.

The previous studies have shown that the high organizational commitment has positive effect on the employees or nurses' work performance. A study conducted by Nikpour (2017) highlights that the high organizational commitment is able to improve the employees' work performance. In addition, Sawitri et al. (2016) points out that the high organizational commitment has positive effect on the nurses' work performance. Furthermore, Khan et al. (2016) finds out that the high organizational commitment affects the improvement of the work performance. 
Based on the previous explanations and the empirical evidence in the abovementioned studies, researchers propose a statement that is formulated in the following hypothesis:

$\mathrm{H}_{5}$ : The high organizational commitment can increase the nurses' work performance.

\section{RESULTS AND DISCUSSION}

The current study applied Structural Equation Model (SEM) analysis method to investigate the gap and the correlation between variables. In order to apply the SEM, the compatibility of the whole model should be approached (Goodness of Fit). Therefore, based on the analysis, it was found that all results are fit.

Based on the data processing the obtained Chi Square value is 198.54. The smaller the value, the more appropriate the model between the theory model and sample data (Dividing the Chi Square value by the Degree of Freedom value). The ideal value is $<3$, it indicates good fit. Based on the divisor result, the obtained value is 1.65 . It indicates the good fit outcome because the value is $<3$. RMSEA value $=0.060$, then the appropriateness is adequate for good fit (RMSEA value is $<0.05$, it indicates close fit, RMSEA value is $<0.08$ indicates good fit, RMSEA value is $<0.10$ indicates marginal fit, and RMSEA value is $>0.10$ indicates poor-fit). ECVI model (with the value equals to 1.64) is compared to ECVI saturated model (with the value equals to 1.86) and ECVI independence model (with the value equals to 38.29). ECVI model is little smaller from ECVI saturated model, and the disparity is bigger than ECVI independence model. In other words, ECVI saturated model is closer to ECVI model than ECVI independence model. In addition, the $90 \%$ confidence interval is 1.45 : 1.87, then it indicates good fit (it exists among ECVI model). AIC model (with the value equals to 301.82) is compared to AIC saturated model (with the value equals to 342.00) and AIC independence model (with the value equals to 7045.58).

AIC model is smaller than AIC saturated model, and the disparity is bigger than AIC independence model. Accordingly, the smaller value indicates good fit. CAIC model (with the value equals to 517.05) is far from CAIC saturated model (with the value equals to 1063.68) and even farther from CAIC independence model (with the value equals to 7121.55). Hence, the smaller value indicates good fit. Normed Fit Index (NFI) value $=0.97$. It is above 0.90, meaning that it indicates good fit. CFI value $=0.99$. It is above 0.90 , then it indicates good fit. Tucker-Lewis Index or Non Normed Fit Index (NNFI) value $=0.99$. It is above 0.90 , then it indicates good fit. Incremental Fit Index (IFI) value $=0.99$. It is above 0.90 , it indicates good fit. Relative Fit Index (RFI) value $=0.96$. It is above 0.90 , it indicates good fit. Parsimonius Normed Fit Index (PNFI) value $=0.76$. It is above 0.6 , so it is applied to analyze the model comparation and it indicates good fit. Critical $N(C N)$ value $=148.31$. It is $<200$, so it does not represent the sample data measurement or marginal fit. If the value is $>200$, then the model represents the data measurement or good fit). Root Mean Square Residual (RMR) is a residual average resulting from the fitting between the variance-covariance matrix from the model and dengan the variance-covariance matrix from the sampel data. Standardized RMR value $=0.065$ shows marginal fit. It is below 0.05 , then it indicates good fit). Goodness of Fit Index (GFI) value $=0.89$ indicates marginal fit. It is above 0.90 , then it indicates good fit. Adjusted Goodness of Fit Index (AGFI) value $=0.85$, it indicates good fit because the value is above 0.90 . Parsimony Goodness of Fit Index (PGFI) value $=0.63$ shows good fit. It is above 0.6 , and it is applied to analyze the model comparison.

Based on the result of the first hypothesis $\left(\mathrm{H}_{1}\right)$ test, it was found that the result supports the first hypothesis $\left(\mathrm{H}_{1}\right)$, which is the healthcare allowance compensation affects the organizational commitment of the nurses who work for two type-A hospitals in Jakarta area. The nurses who receive the compensation will have sense of security at work and emotional ties with the organization. The aforementioned result is also support the study conducted by Nawab et al. (2011) who underline that the indirect compensation has positive correlation with the organizational commitment.

Based on the result of the second hypothesis $\left(\mathrm{H}_{2}\right)$ test, it was found that the result supports the hypothesis with t-value equals to 4.70 . It shows that the satisfaction affects the organizational commitment. The high commitment will motivate the nurses to commit 
themselves at work for the achievement of the goals of the organization and to stay in the organization for a long-term employment. Based on previous studies, several researchers have pointed out that the high job satisfaction can increase the nurses or employees' organizational commitment in an organization. Wang et al. (2012) highlight that the high job satisfaction can increase the nurses' commitment to the organization.

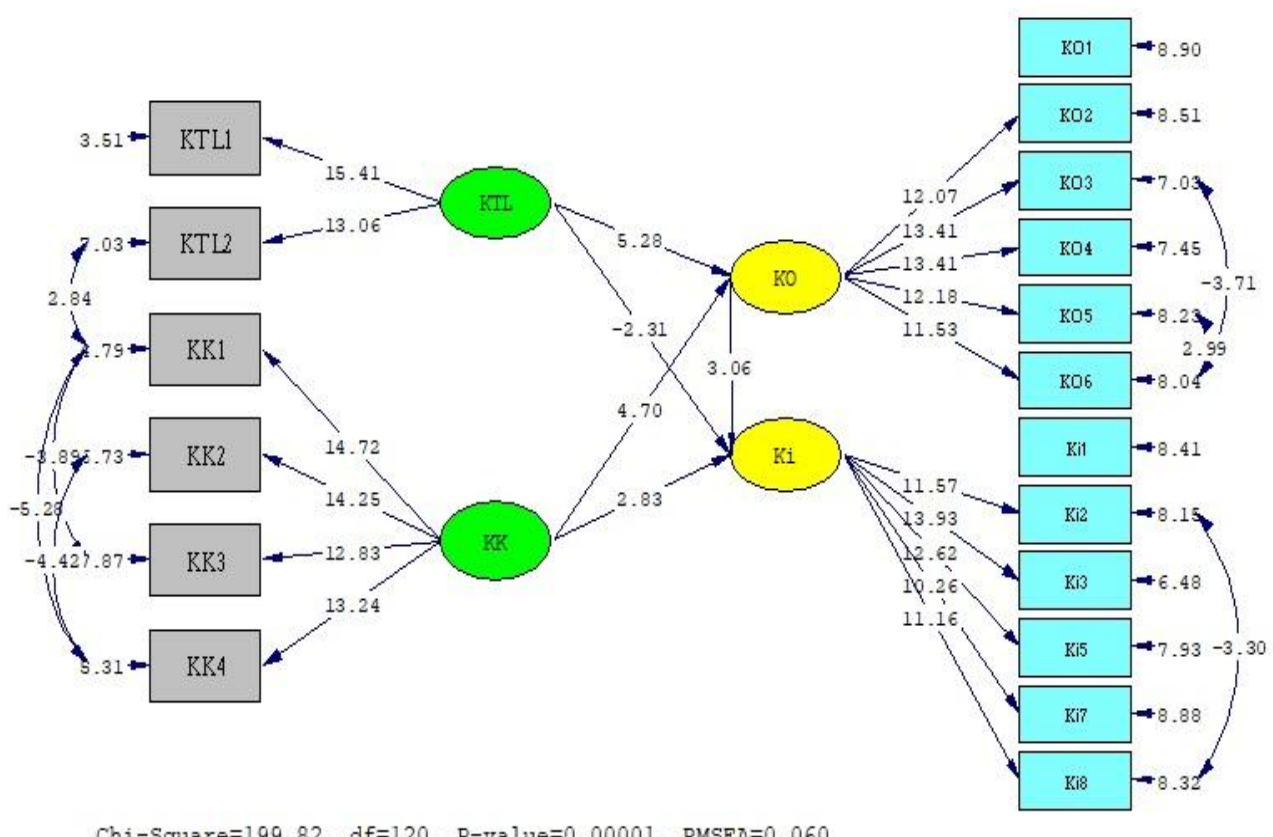

Figure 1 - T-Value Path Diagram

Based on the result of the third $\left(\mathrm{H}_{3}\right)$ test, it was found that the result does not suppport the hypothesis because the t-value equals to -2.31. Accordingly, the shared healthcare allowance compensation does not affect the nurses' work performance. The result of the current study is contrary to the previous study, as both studies investigate different object of the study. The study conducted by Syahreza et al. (2017) shows that the compensation does not affect the increase of the nurses' work performance directly.

Based on the result of the fourth hypothesis $\left(\mathrm{H}_{4}\right)$ test, it was found that the result supports the hypothesis as the job satisfaction affects the nurses' work performance, indicated by the t-value equals to 2.83. The dimensions in the job satisfaction variable create a positive correlation and affect the increase of the nurses' work performance. The nurses' perception and attitudes is closely related to the working environment, type of job, compensation, relation between coworkers, social relation at the workplace, and so on. Therefore, it can be highlighted that the job satisfaction is a condition in which the nurses' desires and needs that are related to their job are fulfilled. The result analysis of the fourth hypothesis support the statement of the previous study conducted by Barasa et al. (2018), which state that the high job satisfaction has positive effect on the increase of the employees' work performance in the organization.

Based on the result of the fifth hypothesis $\left(\mathrm{H}_{5}\right)$ test, it was found that the result analysis supports the hypothesis, which is the organizational commitment affect the nurses' work performance, indicated by the t-value equals to 3.06. The dimensions included in the organizational commitment such as affective commitment, continuance commitment, and normative commitments creates a positive correlation and affect the increase of the nurses' commitment to the work performance. The result of the current study also supports the previous studies conducted by Sawitri et al. (2016) and Nikpour (2017), who underline that the high organizational commitment can increase the employees' work performance.

The current study also explains the two mediation results applied by coefficient multiplier method. The first result is shown from the hypothesis test, which indicates the 
effect of organizational commitment mediating variable between the healthcare allowance compensation and the nurses' work performance. Based on the hypothesis test, the coefficient disparity on the research model, the healthcare allowance compensation affects directly to the organizational commitment with the t value $=5.28$ (it is $>1.96$ ). In addition, the healthcare allowance compensation affects the nurses' work performance directly with $t$ value $=-2.31$ (it is $>1.96$ ). Furthermore, the organizational commitment affects directly on the nurses' work performance with $t$ value $=3.06$ (it is $>1.96$ ). Accordingly, it can be underlined that the organizational commitment mediates the correlation between the healthcare allowance compensation and the nurses' work performance. The second result is indicated by the direct effect of the job satisfaction on the organizational commitment with $t$ value $=4.70$ (it is $>1.96$ ). The job satisfaction affects the nurses' work performance directly with $t$ value $=2.83$ (it is $>1.96$ ). Additionally, the organizational commitment affects the work performance directly with $t$ value $=3.06$ (it is $>1.96$ ). As a result, it can be highlighted that the organizational commitment mediates the correlation between the job satisfaction and the nurses' work performance.

In SEM model, the basic analysis concept is that involves mediator variable when the exogenous variable (independent) is able to affect endogen variable (dependent) through other variable, and it is known as mediator variable $(\mathrm{M})$. It means that the independent variable $(\mathrm{X})$ may affect the mediator variable $(\mathrm{M})$, and the mediator variable $(\mathrm{M})$ affects dependent variable $(Y)$. According Baron and Kenny (1986), the role of variable as the mediator occurs when first, the variation on the independent variable is able to describe the disparity of variation in the mediator variable. Next, the variation in the mediator variable is able to describe the variation in the dependent variable. Last, the mediator variable is being controlled (path a dan path b), and whether there is a disparity or no disparity in the correlation between the independent variable and the dependent variable.

An independent variable can predict the dependent variable directly, but the value is smaller compared to the prediction of the mediator variable. There are two analysis models that involve mediator variable. First, full mediation model, it means that the independent variable is not able to affect the dependent variable positively without the mediator variable. Second, part mediation model, it means that the independent variable is able to affect the dependent variable directly without the involvement of the mediator variable.

\section{CONCLUSION}

Based on the study on the effects of compensation and job satisfaction on the nurses that is mediated by organizational commitment, the current study underlines several points:

The health allowance compensation does not affect the nurses' work performance. Their humanity and oath are what keep them to do their best, with or without the health allowance compensation. Nevertheless, the nurses expect other allowances like extra bonuses, pay rise based on their workload. The next is the statement that the job satisfaction affects the organizational commitment. The current study points out that the job satisfaction can increase the nurses' organizational commitment. It indicates that the job satisfaction is potential element in the improvement of the organizational commitment. Accordingly, the job satisfaction has correlation and effect on the organizational commitment. The higher the job satisfaction of the nurses, the more positive effect it has on the organizational commitment. On the other hand, the less job satisfaction of the nurses will lower the organizational commitment. Furthermore, the dimensions within the job satisfaction variable create positive correlation and affects the increase of the nurses' work performance. The nurses' feelings and attitude are closely related to the working environment, type of job, compensation, the relation between coworkers, social relation at workplace, and so on. Therefore, it can be pointed out that the job satisfaction is a condition in which the nurses' desire and needs are fulfilled. The nurses' motivation to work is the expectation of the rewards. The examples of the expected rewards are bonuses, salary rise, promotion, and appreciation. These rewards are the aspects of financial and non-financial compensation. It indicates that the aspects of the compensation affect to the degree to which an individual performs their task. However, 
based on the third hypothesis $\left(\mathrm{H}_{3}\right)$ test, it was found that result analysis does not support the hypothesis, in which the share of the healthcare allowance compensation does not affect the nurses' work performance.

The current study also measures whether the organizational commitment affects the work performance. Based on the result, the work performance is affected by the organizational commitment. In other words, the high organizational commitment can increase the work performance. It indicates that the hypothesis is accepted. The dimensions of the organizational commitment variable such as affective commitment, continuance commitment, and normative commitment affect directly on the nurses' work performance. The nurses' pride over their workplace is viewed as sufficient. There are some factors that generate their pride; one of them is the management strategy to generate the nurses' excessive enthusiasm to the organization.

The study also points out two mediation results using coefficient multiplier method. The first result shows that there is effect of the organizational commitment mediating variable on the healthcare allowance compensation and the nurses' work performance. Based on the test of the coefficient disparity on the research model, the healthcare allowance compensation does not affect directly on the organizational commitment. The nurses' organizational commitment grow because of the nurses always refer to the nurse oath and they put the humanity as the first priority to serve the patients. Accordingly, the researchers of the current study conducted the interviews to the nurses and inform the respondents that based on the analysis the healthcare allowance compensation shared by the organization does not affect their work performance. Based on the interview, it is revealed that what the respondents want is the extra money as bonus rather than compensation. The second result is that the job satisfaction affects directly on the organizational commitment.

The current study has limitations that may become the consideration for the evaluation in the further studies. The current study applied questionnaire as the research instrument. However, the questionnaire has limitation like response bias in reading and answering the survey. There were respondents' inconsistencies in filling out the questionnaire, or responding the questions based on the desirable ideal condition, not the actual one. Accordingly, the questionnaire may not depict the actual variable. Furthermore, the limited sample data consisting of 185 respondents, the four variables (healthcare allowance compensation, job satisfaction, organizational commitment, and work performance), and the limited dimensions and indicator per variable restrict the current study to do extent investigation on the other factors that can affect the employees' work performance.

Based on the results of the current study, there are several recommendations on the nurses' performance and job satisfaction. First, in order to improve the nurses' work performance in the two type-A hospitals the organization must review the related policy on the healthcare allowance compensation so it will meet the fairness and worthiness principles. The researchers of the current study recommend the organization provides extra money as bonuses and fee raise that are adjusted with the nurses' workload. The reason for that is the result of the current study shows that the shared healthcare allowance compensation does not affect the nurses' work performance. Secondly, the nurses' job satisfaction has to be maintained as the nurses' satisfaction is effective to increase the nurses' work performance. The leaders of the organization may improve the supervision so the nurses' job satisfaction can increase the nurses' work performance. Next, there are some suggestions for further studies. The studies that may be conducted in the future may explore the variables that are not included in the current study, so the study expands more knowledge on the human resources development to the public. In addition, other studies need to be conducted in investigating the factors that affect the nurses' work performance, and the actual factor that increase the nurses' work performance.

\section{REFERENCES}

1. Ahmad, A., Bibi, P., Majid, Abdul H.A., (2016). Co-worker Support as Moderator on the Relationship between Compensation and Transactional Leadership in Organizational 
Commitment. International Journal of Economic Perspectives, 2016, Volume 10, Issue 4, 695-709.

2. Allen, N.J. dan Meyer, J.P. (2012). A Three-Component Conceptualization of Organizational Commitment, Human Resource Management Review, Vol 1, No 1, pp. 61 89.

3. Anari, Nahid Naderi. (2011). Teachers: emotional intelligence, job satisfaction, and organizational commitment. Journal of Workplace Learning. Vol. 24 No. 4, 2012. pp. 256269.

4. Anindita, Rina., Seda, Adventia Emilia., (2017). How Employee engagement mediates the influence of individual factors towards organizational commitment. Consulting Publishing Company, Business Perspectives.

5. Baron dan Greenberg. (1990). Behaviour in organizations. 3rd ed. Boston, MA: Allyn and Bacon ( A Division of Simon and Schuster. Inc.).

6. Fort, A. and Voltero, L. (2004), "Factors affecting the performance of maternal health care providers in Armenia", Human Resources for Health, Vol. 2 No. 8, available at: www.human-resources-health.com/content/2/1/8.

7. Funmilola, O.F., Sola, K.T., Olusola, A.G. (2013). Impact of job satisfaction dimension on job performance in a small and medium enterprise in Ibadan, South Western, Nigeria. Interdiciplinary Journal of Contemporary Research in Business. Vol.4, No.11.

8. Gunawan, A., Barasa, L., Tua, H., (2018). Determinant of Lecturers Work Satisfaction and Implication on Lecturers Performance at Maritime Higher Education in DKI Jakarta. International Review of Management and Marketing, 8(4), 14-23.

9. Gunlu Ebru. (2009). Job satisfaction and organizational commitment of hotel managers in Turkey. International Journal of Contemporary Hospitality Management. Vol. 22 No. 5, pp. 693-717.

10. Khan, Hafiz Ghufran Ali., dan Afzal, Muhammad. (2016). The effect of Reward Systems, Organizational Commitment and Experience on Job Satisfaction with respect to Employee's Perceived Performance. NUML International Journal of Business and Management. Vol. 11, No.2.

11. Khuong, M.N., dan Tien, B.D. (2013). Factors influencing employee loyalty directly and indirectly through job satisfaction - a study of banking sector in Ho Chi Minh City. International Journal of Current Research and Academic Review. Vol.1, No.4.

12. Kuen Wang, M., Hwang, Kevin, P. (2012). The Impact of Employee Perceptions of Human Resource Management Systems on Job Satisfaction and Organizational Commitment during Privatization the Transformations of Privatization: An Empirical Study of Telecommunications Corporations in Taiwan. Asia Pasific Management Review. 17 (3), 321-342.

13. Mcshane., Steven L., Von Glinow., Mary Ann. (2010). Organizational behaviour (fourth Edition). McGraw Hill-International. USA.

14. Nawab Samina, Bhatti, Komal, K. (2011). Influence of Employee Compensation on Organizational Commitment and Job Satisfaction: A Case Study of Educational Sector of Pakistan. International Journal of Business and Social Science Vol. 2 No. 8.

15. Nikpour Amin. (2017). The impact of organizational culture on organizational performance: The mediating role of employee's organizational commitment. International Journal of Organizational Leadership. Volume 6, 65-72.

16. Obasan, Kehinde A. (2012). Effect of Compensation Strategy on Corporate Performance: Evidence from Nigerian Firms. Research Journal of Finance and Accounting. Vol 3, No 7.

17. Okwudili, B. E., Edeh Friday Ogbu. (2017). The Effect of Compensation on Employee Performance in Nigeria Civil Service : A Study Of Rivers State Board of Internal Revenue Service.

18. Pandey., Chetna., dan Rajni Kahre. (2012). Impact of job satisfaction and organizational commitment on employee loyalty. International Journal of Science and Interdisciplinary Research. Vol.1.

19. Robbins, Stephen P. (2006). Perilaku organisasi. Jilid kedua. Jakarta: Prehallindo. 
20. Ruby, Mensah. (2012). "The Impact of Indirect Compensation on Employee Productivity: A Case of Central University College". Tesis. Institute of Distance Learning, Kwame Nkrumah University of Science and Technology.

21. Sawitri. D., Suswati. E., Huda. K., (2016). The Impact of Job Satisfaction, Organization Commitment, Organization Citizenship Behavior (OCB) On Employees' Performance. The International Journal of Organizational Innovation. Vol 9 Number 2.

22. Sedarmayanti. (2007). Sumber daya manusia dan produktivitas kerja. Bandung: Mandar Maju.

23. Simamora, Henry. (2004). Manajemen sumber daya manusia. STIE YKPN, Yogyakarta.

24. Sinambela, Lijan Poltak. (2016). Manajemen sumber daya manusia. Jakarta: Bumi Aksara.

25. Sopiah (2008). Perilaku Organisasi. Yogyakarta.

26. Swanburg, R. C. 2000. Kepemimpinan dan Manajemen untuk Perawat Klinis. Alih bahasa Suharyati Samba. EGC. Jakarta.

27. Syahreza, D. S., Prihatin Lumbanraja, Ritha F. Dalimunthe, Yeni Absah. (2017). Compensation, Employee Performance, and Mediating Role of Retention: A Study of Differential Semantic Scales. European Research Studies Journal. Volume XX, Issue 4A, p. 151. 